\title{
"Rediscovery" of Liang A-Fa: From a Perspective of the 1911 Revolution and Reinterpreting the Taiping Rebellion
}

\author{
Aуити DOI
}

\begin{abstract}
This paper analyzes how the Christian community (exclusively the Protestants in this case) in Guangzhou, Hong Kong, and Macau coped with social transformations after the collapse of the Qing Dynasty and the advent of the 1911 Revolution. There is an accumulation of English-, Chinese-, and Japaneselanguage research about the relationship between the 1911 Revolution and a history of Christianity in China. However, while previous researches focus on the direct impact of Christianity on the Revolution, the current paper analyses how missionaries and Chinese Christians attempted to adapt to social transformations during the Republic era. Given particular attention is the "rediscovery" of Liang A-Fa's (a Chinese Christian in the early 19th century) grave after the 1911 Revolution. These historical findings reveal that the historical reality of Christianity's influence on the Taiping Rebellion was constructed in Guangdong local society after the 1911 Revolution. Also, such construction provides additional insight for interpreting Taiping history.
\end{abstract}

\section{Keywords}

Christianity, Missionaries, Chinese Christians, Taiping Rebellion, Canton (Guangzhou), Hong Kong, The 1911 Revolution, China

\section{Introduction}

This paper focuses on how Christian churches in Guangdong, Hong Kong and Macau adapted to social changes resulting from the demise of the Qing Dynasty 
following the 1911 Revolution. There are many studies on the 1911 Revolution and Christianity, the majority of which are limited to the argument over how Christian churches took part in the Revolution. ${ }^{1}$ This paper does not attempt to directly link Christian churches and the Revolution, ${ }^{2}$ but rather aims to analyze a history of Christianity through studies of the post-revolution Taiping Heavenly Kingdom.

It is well known that the Taiping Heavenly Kingdom was an anti-Qing movement led by the God Worshippers under Hong Xiuquan. Hong and his disciples were inspired by Good Words Exhorting the Age-a collection of Christian tracts. ${ }^{3}$ Scholarly accounts also point out that Hong, inspired by Christian ideas, revolted against Qing Dynasty at the middle of $19^{\text {th }}$ century. Yet, scholars, especially in China, usually do not emphasize on the fact that the uprising resulted from an expansion of Christianity in China. Liu Chengyu at the end of the Qing Dynasty, and Wu Lingqing in the Republic Era, described the mobilization process of the God Worshippers but provided few details on Christianity and the Worshippers as a movement. ${ }^{5}$ Moreover, without providing details on Chinese society at the time, recently published research merely states that the religious aspects of this uprising began drawing attention in the United States and Europe in the 1950s. ${ }^{6}$

According to Yorihisa Namiki, who studied how the Taiping Heavenly

\footnotetext{
1 Jinqiang Li, "Xianggang Daoji Huitang Yu Qingji Geming Xin Yundong” [Hong Kong To Tsai Church and Qingji New Revolutionary Movements], in Zhongguo Jidujiao Quyushi Yanjiu [Historical Studies of the Chinese Christian Districts] ed. Jianming Chen and Jiafeng Liu (Sichuan: Bashu Publisher, 2008), 127-41 argues the relationship between Christianity in Hong Kong and revolutionary movements during the end of the Qing Dynasty.

2 If not specified otherwise, Christianity in this paper refers to the various Protestant sects.

${ }^{3}$ Seiichiro Yoshizawa, Shincho to Kindai Sekai: 19 Seiki [The Qing Dynasty and the Modern World: 19th Century] (Iwanami, 2011), 62-66; Hideaki Kikuchi, "Taihei Tengoku ni Miru Ibunka Juyo" [Taiping Heavenly Kingdom and Acceptance of Different Cultures], Sekaishi Libretto 65, (2003): 14-20.

${ }^{4}$ Zhou Han from Hunan wrote Guijiao Gaisi [The Demons' Call for Death] during the late Qing Period. This book argues against Christianity, saying that Hong Xiuquan's religious belief caused the war: Zhigang Li "Wanqing Guangdong Jidujiao Jiaoan Zhi Shixi” [A Preliminary Analysis of Anti-Christianity Cases at Guangdong during the Late Qing Era], in Jidujiao Yu Jidai Zhongguo Wenhua Lun Wenji 2 [Collection of Papers on Christianity and Modern Chinese Culture, Vol. 2] ed. Zhigang Li (Taiwan: Yuzhou Guang Chubanshe, 1995), 143-144; Jiang Sun, "'Youkyo' to Iu Tasha: 19 Seiki Kouhan ni Okeru Kirisuto Kyo to Chugoku Shakai" ["Foreign Religion" as the Other: Christianity and Chinese Society in the Latter Half of the 19th Century], Rekishi Gaku Kenkyu [Journal of Historical Studies] 808, (November 2005): 29.

${ }^{5}$ Chengyu Liu, Taiping Tianguo Zhanshi [War History of the Taiping Heavenly Kingdom] (Zuguo Zazhishe, 1904), 2; Lingqing Wu, Taiping Tianguo Yeshi [Privately Composed History of the Taiping Heavenly Kingdom] (Shanghai: Zhonghua Shuju, 1923), 1-2.

${ }^{6}$ Feiya Tao and Weihua Yang, Jidujiao Yu Zhongguo Shehui Kexue Yanjiu Rumen [Introduction to Christianity and Chinese Society] (Shanghai: Fudan University Chubanshe, 2009), 60-65.
} 
Kingdom became known within the historical context of the Revolution, "Sun Yat-sen, as a Cantonese, aimed to better appeal to the public by stressing the continuity of works left unfinished by Hong." It is true that Sun wanted to legitimize their regional revolution in Guangzhou by linking it with anti-Qing movements. However, he does not answer when the linkage between the Heavenly Kingdom and Christianity was established. It is also well known that Sun was a Christian and that he had mentioned the Heavenly Kingdom. However, this discourse stops short of linking Christianity and the 20th century revolution. To the best of the current author's knowledge, there are almost no historical materials that argue a connection between Christianity and the Heavenly Kingdom. ${ }^{8}$ Rong Hong, who received thoroughly Christian education on his early days, reviewed on his memoir published at 1909 that "the Heavenly Kingdom showed no signs of Christianity, even at Nanjing where it had been located for a decade, and Guangxi, where it originated." In other words, the relationship between the Heavenly Kingdom and Christianity had already been largely forgotten at the end of the Qing era. ${ }^{9}$

How did the relationship between the Heavenly Kingdom and Christianity come to be known? Namiki's paper suggests that overseas historical materials on the Heavenly Kingdom appeared in China during the 1920s and the 1930s. ${ }^{10}$ There is no doubt that newly discovered historical materials have gradually enabled Chinese scholars to realize the extent of the influence of Christian ideas on the Heavenly Kingdom. However, these materials have not answered all important research questions. Early in the Heavenly Kingdom's mobilization, foreign missionaries such as Theodore Humberg propagated it as a Christian movement in China. Would this event not lead to research on the convergence between the Kingdom and Christianity among later missionaries or Chinese Christians? In other words, in addition to anticipated answers regarding the research question I have raised, dynamics within Chinese society should also be considered.

In this regard, it is important to pay attention to Chinese missionary Liang A-Fa (1789-1855). Known as the first Chinese missionary, Liang's religious tracts, Good Words Exhorting the Age, written in 1832, is said to have influenced Hong Xiuquan's views on Christianity. Therefore, we may hypothesize that a common

\footnotetext{
${ }^{7}$ Yorihisa Namiki, “"Taihei Tengoku' Zou no Keisei to Henbo" [The Construction and Change of the Image of the 'Taiping Heavenly Kingdom'], in Nengun to Kahoku Shakai: Kindai Chugoku ni Okeru Minshu Hanran [Nien Rebellion and the North Chinese Society: Popular Uprising in Modern China] (Kenbun Shuppan, 2010), 471.

${ }^{8}$ For example, Hidemi Onogawa and Ryuusuke Miyazaki (eds.), Miyazaki Touten Zenshuu, (Vol 1, Heibonsha, 1971), 478.

9 Hong Rong, Seigaku Touzenki [My Life in China and America], trans. Hiromu Momose (Heibonsha, 1969), 110.

${ }^{10}$ Namiki, 473-474.
} 
ground between the Heavenly Kingdom and Christianity was established due to a later "discovery" of Liang and evaluation of his works.

To verify this hypothesis, this paper uses the McNeur Family Papers (MFP) of the Hocken Collection at the University of Otago. The MFP contains materials about George Hunter McNeur (1874-1953), who went to China in 1901 and dedicated himself to mission works mainly in Guangzhou until 1938. He is known as an author of a biography, China's First Preacher: Liang A-fa Liang $A-F a$ 1789-1855, for which he conducted extensive research (refer to Section 3 for details). ${ }^{11}$ Examining materials he left enables an analysis of how Liang A-Fa was "discovered" in the 20th century and how he was involved in researching the Heavenly Kingdom.

\section{1. "Great Men" Appeared}

\section{(1) Shi Jianru: In Memory of Revolution Martyr}

Triggered by the uprising in Wuchang, Hubei Province, in October 1911, each province began declaring independence from the Qing Government. The Republic of China was founded in January 1912 with Sun Yat-sen as its Interim President. The Qing Dynasty ended in February as the Xuantong Emperor abdicated from the throne. Liang A-Fa appeared in the third issue of the Christian daily paper, Daguangbao, which was launched in February 1913 in Hong Kong. ${ }^{12}$ However, it is difficult to imagine that Liang was a well-known figure among Christians in Guangdong and Hong Kong, as he was only one of the many "great men" of Christianity "discovered" in this region during this time. This section will focus on those "great men" who were "discovered" after the Xinhai Revolution.

The day of June 7th was an anniversary of foundation of Lingnan University, formerly estab-lished at 1888. Although Liang A-Fa's grave was transferred and his memorial monument established by the Vice President of Lingnan University, his name was mentioned in only five lines of the 37-line article about the ceremony. ${ }^{13}$ Actually, more attention seemed to be paid to Shi Jianru. Shi entered

\footnotetext{
${ }^{11}$ George Hunter McNeur, China's First Preacher: Liang A-fa 1789-1855 (Shanghai: Kwang Hsueh Publishing House, Oxford University Press, China Agency, 1934). The Biography of Liang A-fa, as is clear from the third section of this article, has undergone a complicated process of publication in Chinese and English. This article specifically distinguished between the two. Chinese editions were issued in 1930 and 1955. Hence, I transcribe the English edition published in 1934 as the Biography of Liang A-fa and the Chinese edition published in 1930 and 1955 as Liang A-fa Zhuan (1930/1955) in Pinyin style in text for readers' convenience.

12 Zhuling Zhang, "Lundun Hui Lishi Nan-Zhongguo Fangmian" [History of London Churches in Southern China], Shanghai City Archive U133-0-159, 5.

13 "Xiaozuri" [School Anniversary], Lingnan Qingnian Bao [Lingnan Youth], June 24, 1920,
} 
the Christian College in China, the predecessor of Lingnan University, in 1898, and became a member of Xingzhonghui (Revive China Society) the next year. Taking advantage of the 1900 Huizhou Uprising, he attempted an assassination of the Viceroy of Liangguang, but his assassination failed and Shi was executed in November that year.

Soon after the establishment of the Republic in July 1913, Sun Yat-sen collected financial support from different sources and built a statue of Shi on Qingcai Hill at the Martyr South Boulevard (Xianlie nan lu) to commemorate him as a martyr of the uprising. ${ }^{14}$ An article from Lingnan University argues that while it was a pity that the university was unable to build his statue on campus, students should visit his grave on Sundays to appreciate his spirit. Doing so would be a "good opportunity to acquire patriotism." In other words, the article saw Shi as a "great patriotic figure" and a model for Lingnan University students. ${ }^{15}$ In a similar vein, faculty members at Lingnan told affiliated elementary school students about Shi's execution as a "great man of the Republic."16 These facts reveal how well-known Shi was within the university.

At that time, a social reformation movement launched by Christian association has been welcomed broadly. When Ryan Dunch suggested, "The early Republican period was, then, a time of expansion on membership and facilities for the Protestant churches in the Fuzhou area." 17 This situation is also similar to Guangzhou. Zhong Rongguang appealed to students to actively engage in social transformation. He avers, "no religion except for Christianity could eliminate the custom of polygamy. ${ }^{18}$ Such statements show how Shi was a model for Christian students and a "patriotic great man" ambitious enough to transform the late Qing society. In other words, Shi was well known within Christian universities as someone who could link the previous revolution to subsequent social transformation.

Page 2.

14 Ziyou Feng, "A Brief Biography of Shi Jianru," in Geming Yishi 2 [History of the Revolution, Vol. 2] (Beijing: Xinxing Chubanshe, 2009), 832-836. After the Xinhai Revolution, some spoke highly of Feng, arguing that his belongings should be returned to his family, "A, Shi Jianru Busiyi" [Alas, the Undying Shi Jianru], Xianggang Huazi Ribao [Hong Kong Chinese Daily], December 26, 1911; "Geihuan Shi Lieshi Chanye" [Returning to Martyr Shi], Xianggang Huazi Ribao [Hong Kong Chinese Daily], March 21, 1913.

${ }^{15}$ Zhu, "Lunshuo: Liyong Jihui Yi Xiqu Aiguo Jingshen" [An Opportunity to be Imbued with Patriotism], Lingnan Qingnian Bao [Lingnan Youth], October 11, 1917, Page 3.

16 "Tinggu" [Listening to the Old Times], Lingnan Qingnian Bao [Lingnan Youth], October 18, 1917, Page 1.

17 Ryan Dunch, Fuzhou Protestans and the making of a Modern China 1875-1927, New Heaven and Londn: Yale University Press, 2001.

18 Guanwei Lu, "Xuesheng Yu Guojia" [Students and the Country], Lingnan Qingnian Bao [Lingnan Youth], September 27, 1917, Page 3. This article was based on Zhong Rongguang's speech. 


\section{(2) Cai Gao: The First Chinese Christian}

Originally from Xiangshan, Guangdong Province, Cai Gao was known as the first Chinese convert who was baptized in 1814. Cai's descendants at Jiangxi published his biography in Tongwenbao, a Christian periodical published in Shanghai, in 1914. ${ }^{19}$ The same year, Zhang Zhuling, a pastor of To Tsai Church (Daoji Huitang) in Hong Kong, identified the location where Cai Gao was baptized in Macau. He also introduced his profile for Chinese Christians by citing from Robert Morrison's diary. ${ }^{20}$ Furthermore, even China Mission Year Book also estimated that the history of self-supporting church in China came from Cai's baptism at 19th century. ${ }^{21}$ This article explains how Cai Gao was well received among the Chinese Christian community, and his reputation only got better against the backdrop of an increase in churches built by Chinese in the post-Xinhai Revolution era.

Church building had gained momentum since 1898 among Macau Chinese in Hong Kong, where Morrison's grave stands and where Cai Gao was baptized. Although it was difficult for Zhang's To Tsai Church to obtain permission from the Portugal authority, Cai Gao Memorial Hall was established in 1918. ${ }^{22}$ Also, the same era saw an anti-opium movement surging in Macau. ${ }^{23}$ Thus, Cai Gao was perhaps just the person needed in Macau, where the Christian community was promoting a social gospel movement and society was trying to ban opium. Cai became popular in no time. Accompanying Chen Jiwu, a professor at Lingnan University, and Wang Zhengting, an official at the ministry of foreign affairs, in October 1917, Zhong Rongguang attended the cornerstone laying ceremony for Cai Gao Memorial Hall. ${ }^{24}$

Cai Gao was very famous among Chinese Christians in the late 19th century,

19 Zhuling Zhang, Lundun Hui Lishi Nan Zhongguo Fangmian, 5. The author has not identified the original part of Tongwenbao appearing here.

${ }^{20}$ Zhuling Zhang, trans., "Zhonghua Diyi Shouxi Ren Cai Gao Jun Yishi” [Unknown Stories of the First Baptized Chinese: Cai Gao], in Guangdong Jidu Jiaohui Xiejinhui Baogao 1914 Nian [Guangdong Xiejin Christian Church Report of 1914], Shanghai City Archive U12324-1, 13-16.

${ }^{21}$ Y. Y. Tsu, "Progress and Fruits of Christianity in China," in China Mission Year Book, 1913 (Shanghai: Christian Literature Society China, 1913), 117.

22 Zhuling Zhang, trans., "Zhonghua Diyi Shouxi Ren Cai Gao Jun Yishi," 19-20.

23 Tatsuya Koizumi, "Makao kara no Ahen Mitsuyu Mondai to Igirisu Teikoku: 1913 nen Ahen Kyotei wo Chushin ni" [The Problem of Opium Smuggling from Macau and the British Empire: The Opium Convention of 1913], in Teikoku no Nagai Kage: 20 Seiki Kokusai Chitsujo no Henyou [The Long Shadow of the Empire: Transformation of the 20th Century International Order], ed. Youichi Kibata and Harumi Gotou (Minerva, 2010), 146.

24 "Jiangmen Fenxiao Zaizhi," [About the Jiangmen Branch Campus] Lingnan Qingnian Bao [Lingnan Youth], October 11, 1917, Page 1. Zhong negotiated with financial supporters in Jiangmen to manage Lingnan University's Jiangmen Branch Campus. 
and it is undeniable that he was the first Christian in the history of Chinese protestant missionaries. ${ }^{25}$ However, as discussed below, Liang A-Fa's "discovery" contrasts to Cai Gao's case.

\section{The" Discovery" of Liang A-Fa and the Description of the Heavenly Kingdom}

\section{(1) Liang A-Fa's Descendants and His Son-in-Law's Effort to Award Him}

It is clear from the previous section that after the collapse of the Qing Dynasty, Christians in Guangzhou and Macau earned a good reputation. How did the public come to know Liang A-fa in such an era? This section examines this process concentrating on Feng Yangong's role.

Feng Yangong, who married Liang A-Fa's great-granddaughter Peifang, played an important role in commemorating Liang A-Fa. While little is known about Feng, according to Lin Xiyi ( 希逸) who was from the same town as Feng, he was a Christian originally from Xincun Tengyong, Nanhai-County. During the last years of the Qing Dynasty, Feng educated ethnic Chinese in Kuala Lumpur and Selangor. During his mission, Feng also propagated on the revolution to Overseas Chinese at banks and manufacturer unions at different seaports.26 Since Zhang Zhuling points out that Feng was an organizer of the Yisai Association, founded by a Methodist Church, he may have been an activist engaging in revolutionary movements at the end of the Qing Dynasty.27

After Feng married Liang A-Fa's great-granddaughter in 1911 in Guangzhou, he returned to Kuala Lumpur. In a letter from his father-in-law, Liang Zelan, Feng learned that his family descended from Liang A-Fa, and that the tombs of Liang, Liang's father, Chongneng, and wife, Li, were about to be removed due to an enlargement of Lingnan University. Feng wrote a letter to the university, appealing

\footnotetext{
${ }^{25}$ Missionaries provide similar accounts. In a long article from The Chinese Recorder, where early missionaries were introduced, Morrison was said to have been baptized by Cai Gao, whereas Liang A-fa received no mention: E. Box, "Morrison, Milne, and Medhurst: Three Pioneers of Protestant Missions to China," The Chinese Recorder, (March 1904): 122.

${ }^{26}$ Xiyi Lin. "Buwang Zhi Wangshi Shulue" [Brief Recollections], Jidujiao Zhongguo Diyi Chuanjiaoshi Leung Ah-Faat Zhuan [The Biography of the First Chinese Missionary-Liang A-fa], 27-28, Papers in Chinese script relating to Leung Faat (MS-1007-003/026), MFP. The original document counts two pages as one. This paper follows the same numbering scheme.

27 Zhuling Zhang and Yaoshi Pi, trans., Zhongguo Jiduhui Diyi Xuanjiaoshi Liang A-fa Xiansheng Zhuan Lue [A Brief Biography of the First Chinese Christian Missionary-Liang A-fa] (Hong Kong: Hong Kong Christian Periodicals of Hong Kong Daguangbao, 1923), 9, Various pamphlets written in Chinese script (MS-1007-003/030), MFP.
} 
for the preservation of his ancestors' graves.28 This appealing must be the reason why Liang A-Fa became known to Chinese people as well as Chinese Christians. However, the process along the way was complicated.

First, the previous section touched upon Feng's relationship with Cai Gao. After the Xinhai Revolution, Feng returned to Kuala Lumpur to resumed mission works. There he took notice of an article that Zhang Zhuling wrote about Cai Gao, extolling him as the first Chinese Protestant. Feng wrote to Zhang, rebutting that Liang A-fa was the first convert. Later, Zhang said, "there were some verbal disputes between the two." Thus, perhaps some arguments occurred between the Liang and Cais. ${ }^{29}$

McNeur concurred with Zhang: "through article in Xn (Christian) paper in Hong Kong about Tsi'oi Ah Ko being first Xn, Mr. Feng was moved to claiming that Liang A-Fa was the first Xn. Contraversy led to investigation \& discovery of Liang A-Fa 's grave within property of CCC (Canton Christian College, or Lingnan University) and moving of remains to centre of compound. ${ }^{, 30}$ Since there are materials about Cai Gao among those about Liang A-Fa in $M F P$, it is very likely that Feng Yangong and Zhang Zhuling provided such materials. ${ }^{31}$

Second, it turned out badly for Feng Yangong as the grave could not be identified. Liang Zelan recalls that the grave was on a hill called Xin Fenghuang Gang. In a reply, Zhong Rongguang says, "there is a village called Xin Fenghuag Gang near our school, but there are no hills of such a name. We have sent people to search around the mountains and hills after receiving your letter, and had Mr. Li Yuehan visit Liang's descendants." Zhong did all he could to find the grave, but could only identify that of Chongneng. ${ }^{32}$

Third, almost all of Liang A-Fa's belongings were lost due to a disastrous flood in 1915 close to Henan, where Liang lived. Upon his son-in-law's request, Liang Zelan collected Liang A-Fa's belongings and left them to his friends, but they

${ }^{28}$ Zelan Liang, "Guanyu Liang A-fa Xiansheng Fenmu Shi Laiwang Gongdu Yice” [Official Documents about Liang A-fa's Grave], in Zhongguo Jiduhui Diyi Xuanjiaoshi Liang A-fa Xiansheng Zhuan Lue [A Brief Biography of the First Chinese Christian Missionary-Liang A-fa], 23-24.

${ }^{29}$ Zhuling Zhang and Yaoshi Pi, trans., 10.

${ }^{30}$ Notebook containing material relating to Leung Ah Faat (MS-1007-003/018), McNeur Family Paper.

${ }^{31}$ Zhuling Zhang, "Zhidaotang Zhijin Xitan" [Recollections of Zhidaotang], Zhidao Annual, December 1928, Annual report of the Chinese Christian Church of Macau (MS-1007-003/033) MFP; "Cai GaoXiansheng Nianpu" [Cai Gao Biography], Tongwenbao 630, Miscellaneous papers (MS-1007-003/028), MFP; "Cai Gao Xiansheng Shilue" [A Brief Biography of Cai Gao], Notebook containing material relating to Leung Ah Faat, MFP.

32 "Rongguang Jun Fuhan Zhaolu" [A Record of Rongguang's Letters], August 15, 1917, Zhongguo Jiduhui Diyi Xuanjiaoshi Liang A-fa Xiansheng Zhuan Lue [A Brief Biography of the First Chinese Christian Missionary - Liang A-fa], Papers in Chinese script relating to Leung Faat (MS-1007-003/026), MFP. 
were lost before they could be introduced to the public. ${ }^{33}$ This disaster obviously made proving Liang A-fa's accomplishment even harder.

Regardless of these difficulties, Feng Yangong spoke with Cheng Jiwu, who was from the same university, at Kuala Lumpur and negotiated with Zhong Rongguang and others after returning to Guangzhou. Finally, he was able to "receive satisfactory answers" at the end of $1917 .{ }^{34}$ Later, Liang's descendants provided clues from their memories that led to the "discovery" of the grave at Xiao Gang, to the west of Lingnan University. ${ }^{35}$

To commemorate the achievement of his grandfather-in-law, Feng made patient efforts, as he was strongly concerned about Cai Gao as the first Chinese protestant. Although there are still some unclear points regarding exchanges between Feng Yangong and Lingnan University, MFP and other materials seem to indicate that it was Feng who "discovered" Liang A-Fa.

In his later years, Zhang Zhuling recollected on the dispute between the Cai and the Liang A-Fa families regarding who the first Chinese protestant was. With cynicism, Zhang sneered, "That dispute was truly meaningful.",36

\section{(2) Zhang Zhuling's "Linkage" of the Taiping Heavenly Kingdom and Christianity}

As a result of Feng Yangong's effort to commemorate Liang A-fa, Liang's grave was relocated to the campus of Lingnan University on June 7, 1920. Encouraging missionaries to commemorate Liang A-Fa's accomplishment, McNeur learned the existence of Liang's grave, saying, "It is hoped that the sacred spot may be preserved and some worthy memorial erected to the memory of the pioneer evangelist." ${ }^{37}$ Liang's gravestone reads, "Leung Fat-First Chinese Preacher," to differentiate him with the accomplishments of Cai Gao. ${ }^{38}$

However, for Zhang Zhuling, who participated in revolutionary movements

\footnotetext{
${ }^{33}$ Zelan Liang.

${ }^{34}$ Zelan Liang, 27. There is no evidence showing that Chen Jiwu was in Southeast Asia during this period. However, ethnic Chinese originally from Macau provided monetary support, and Edmund from Lingnan University raised funds. These seem to indicate that Chen was in communication with the University: Dianlai Jukuan [Large Amount of Money Wired], Lingnan Qingnian Bao [Lingnan Youth], October 18, 1917, Page 2; "Weiwo Huaqiao" [Consoling the Ethnic Chinese], Lingnan Qingnian Bao [Lingnan Youth], March 1, 1918, Page 2.

${ }^{35}$ Feng Yangong sent a picture on which it was written that Liang A-fa's grave was in Xiaogang: Photographs and papers (MS-1007-003/038), MFP; "Diyi Xuanjiaoshi Liang A-fa Xiansheng Mu" [The First Missionary—Liang A-fa's Grave], which was transferred from Xiaogang to Lingnan University, also records the process of the grave's transfer. (This was confirmed by the author at Guangzhou Sun Yat-sen University Library in September 2008).

${ }^{36}$ Zhuling Zhang and Yaoshi Pi, trans., 9.

37 Geo H. McNeur, "Summer Conference for Preachers at Canton," The Chinese Recorder, (September 1918): 623-624.

38 "Diyi Xuanjiaoshi Liang A-fa Xiansheng Mu."
} 
during the late Qing Period and promoted "independent churches" for Chinese people, it was trivial whether Liang Ah-Faat was "the first Christian" or "the first Chinese Preacher" Rather, the important point was how Liang's Good Words Exhorting the Age has been evaluated.

Why did the work [Good Words Exhorting the Age] so quickly become a commemorative masterpiece in China? During the early years of the Taiping Heavenly Kingdom, Hong Xiuquan learnt Jesus's preaching and inspired his followers. This little pamphlet became the major factor for the then national revolution. [However,] this relationship is nothing new (because today people say that published materials by the Christian Literature Society for Chinese drove the revolution). ${ }^{39}$

It is clear from this passage that Zhang Zhuling saw the Christian missions and the Taiping and 1911 Revolutions all in one continuation of history. The Christian Literature Society for Chinese was a Christian publisher established in Shanghai in 1887. Its Wanguo Gongbao (A Review of the Times) advocated for political reforms during the One Hundred Days' Reform and the Xinhai Period. These claims were broadly accepted by Chinese politicians and intellectuals at the time. ${ }^{40}$ Zhang Zhuling seems to have understood the similarities between the Christian Literature Society for Chinese's impact during the late Qing Era and the influence that Good Words Exhorting the Age had exerted on Taiping Heavenly Kingdom. For Zhang Zhuling, Liang A-Fa (who was made known to the public by Feng Yangong), was key in connecting the Taiping Heavenly Kingdom and Xinhai Revolution with Christianity.

How did Christianity link the anti-Qing campaign in the 19th century and the Xinhai Revolution in the 20th century? Zhang Zhuling's family background might have influenced his actions. His grandfather, Caiting, had contacts with Hong Rengan, who hid himself at Dongguan's Niumianpu to escape the Qing Government's tracking. Inspired by Hong's "national revolution thoughts," Caiting went to Tianjing (Nanjing) and, but reportedly died in 1864 at Hangzhou. To dodge Qing investigations over his relations with the Taiping Heavenly

39 Jidu Jiao Zhongguo Diyi Xuanjiaoshi Liang A-fa Xiansheng Zhuan [Biography of Liang A-fa, the First Missionary in China], 12.

40 Zhigang Li, "Guangxuehui Zhi Fazhan Yu Zhonguo Shiju Zhuanbian Zhi Guanxi" [The Relationship between the Development of the Christian Literature Society for Chinese and China's Transformation to a New Era], in Jidujiao Yu Jidai Zhongguo Wenhua Lunwenji 2 [Collection of Papers on Christianity and Modern Chinese Culture, Vol. 2], ed. Zhigang Li (Taiwan: Yuzhouguang Chubanshe, 1989), 284-285; Changsheng Gu, Xuanjiaoshi Yu Jindai Zhongguo [Missionaries and Modern China] (Shanghai: Shanghai Renmin Chubanshe, 1985), $156-161$. 
Kingdom, Zhuling's father, Shenghe, was sent to a Christian school at Lilang, and became a pastor of the Basel Mission. Being a Hakka himself, Shenghe was a trusted figure among Hakka inside and outside the country after promoting his faith among Hakka Chinese living in Hong Kong and Dongguan (but with plans to go abroad) and helping overseas Hakka Chinese transfer money. With the income from these activities he established churches and educated people at different locations of Hong Kong. ${ }^{41}$

Having long planned to build a church in his hometown, Shenghe saw an opportunity in the Xinhai Revolution and made a Christian village at Niumianpu. According to Liu Yuesheng, a historian specializing in Christianity during the Republican Era, "After the Republic gained independence and everything was refreshed, [Zhang Shenghe came back from Hong Kong and] arrived home on the last day of the year. He gathered everybody in his tribe and gave an all-night speech, strongly recommending them to abandon icons and believe in God. In addition, he encouraged people to make a new village named Yongan." ${ }^{42}$ Zhang's preparation for Yongan Village had been carried out in Dongguan Village, which was secluded from urban areas. Therefore, the preparation process was probably not extensive.

Zhang Zhuling established an epitaph at Dongguan Niumianpu to commemorate his grandfather, Caiting's, accomplishment. It reads as follows:

A forerunner who helped Christianity bear fruit in Dongguan.

His personal revolution had political implications

The uprising demolished the Manchurian Dynasty

Left his name in the history of the Heavenly Kingdom

Dead in Hangzhou, never indulged in rest

Who does not have ancestors and who can deny their spiritual bond

Here we inscribe their gravestones in their memory, for both loyalty and piety,

Our ancestors always on our minds

Written by grandson, Tingxian (Zhuling). ${ }^{43}$

\footnotetext{
${ }^{41}$ Aosheng Liu, The History of Christian Churches in Hong Kong (Hong Kong: Hong Kong Baptist Church, 1997), 342.

42 Liu, The History of Christian Churches in Hong Kong. Today, instead of Yongan Village, this place is commonly called Niumianpu Village (author's field work in July 2010 and February 2011).

43 Tingxian (Zhuling) Zhang, "Beizhi" [Epigraph], Zhanggong Caiting Jinianbei [The Monument for Zhang Gongcai] (confirmed by the author in Dongguan Niumianpu Village in February 2011). The author would like to thank Hajime Miyauchi, Yoshihiko Kubo, Akiko Kurata, and Zeng Fuquan, and others who provided generous help and support in visiting Niumianpu Village.
} 
The epitaph points out that Zhang Caiting was a founder of the Dongguan Church and that as a Christian was compassionate with the Heavenly Kingdom, which caused the collapse of the Manchurian Dynasty. Caiting's personal "revolution" seems to have been "related" to the "politics" of China. This relationship is suggested in the passage: "(The prising) demolished the Manchurian Dynasty." Vividly indicating the connection between the Taiping Heavenly Kingdom and Christianity, this memorial epitaph was said to have been erected in 1916.

Thus, Zhang Zhuling's understanding of the Taiping Heavenly Kingdom was based on the experiences of his grandfather (who was influenced by Hong Rengan) and father (who created a new Christian village with the conviction that the revolution manifested a new religious era).

\section{(3) Perception of the Heavenly Kingdom in Guangdong and Hong Kong after the 1911 Revolution}

This epitaph has showed that the Zhang family of Dongguang Niumianpu was related to the Heavenly Kingdom Uprising and the Church. However, different sources indicate that ties between the Heavenly Kingdom and Christianity influenced not only Zhang Zhuling, but also other famous figures in Guangdong.

For example, Zhong Rongguang recognized that revolutionary leaders since Hong Xiuquan and Sun Yat-sen all graduated from these schools. ${ }^{44}$ This indicates that Zhong saw a linkage between Hong and Sun within a common context of Christianity. The perceptual linkage of the Heavenly Kingdom and Christianity spread not only among pastors like Zhang, but also famous figures of the Chinese Christian Elites like Zhong Rongguang. Zhong sought refuge at the To Tsai Church during the chaotic times of the Hundred Days' Reform and Boxer Rebellion. He had a close relationship with Zhang Zhuling. ${ }^{45}$ Therefore, it may not have been difficult to accept Zhang's perception of the Heavenly Kingdom.

The thoughts of Zhang and Zhong influenced Jian Youwen. Graduating from Lingnan University in 1917, Jian specialized in Religion and Education Studies at the University of Chicago. During his stay in the United States, he worked on the relationship between the Heavenly Kingdom and Christianity, though he had to give up his research after his father's illness. He continued his research on the Heavenly Kingdom and taught at Yanching University. From November to December 1923, Jian interviewed the descendants of the ex-member of the

\footnotetext{
${ }^{44} \mathrm{Lu}, 3$.

45 Alumni Association of Hong Kong Lingnan University, Zhong Rongguang Xiansheng Zhuan [The Biography of Zhong Rongguang] (Hong Kong: Alumni Association of Hong Kong Lingnan University, 1996), 20-21.
} 
Heavenly Kingdom. Interestingly, these interviews were arranged by Zhang Shenghe and Zhang Zhuling. The Zhangs introduced Jian to Hong Xiaoyun (a journalist studying the Heavenly Kingdom) in Hong Kong and Hong Xianchu (grandson of the Lang King of the Heavenly Kingdom) in Guangzhou. ${ }^{46}$.

According to Jian, the Heavenly Kingdom was a national revolution, and similar to those led by Zhu Yuanzhang, who overthrew the Yuan Dynasty, and Sun Yat-sen, who launched campaigns against the Qing Dynasty. However, the Kingdom was also distinct in that it was both a religious and a political entity. Jian argues that the Heavenly Kingdom was a trinity revolution, combining the religious, the national, and the political. ${ }^{47}$ This statement cannot be separated from his personal background as a Christian from Lingnan University. Also, prior to his participation in the Northern Expedition with Feng Yuxiang after becoming a member of the Kuomintang, Jian received support from Zhang Zhuling for his research.

In the 1950s, Jian explained in a footnote in his work about Christian missions, "The first Christian Chinese leader was Hong Xiuquan of the Heavenly Kingdom, the second was Sun Yat-sen of the Republic of China, and the third was President Chiang Kai-shek." 48 To Jian, a Christian originally from Guangdong and a member of the Kuomintang, Christianity and revolution were always two sides of the same coin.

Recently published photographs confirm that in September 1924 a gathering was held at Liang A-Fa's grave to commemorate him. Whether this was held regularly is not clear, but it can be inferred that Liang was a well-known Christian figure among students and faculty members at Lingnan University. ${ }^{49}$ Liang was also known among students, elementary school pupils, and faculty staff members at Lingnan University and its affiliated institutes, which served as a catalyst for the general public to notice the connection between the Heavenly Kingdom and Christianity. In addition, Zhong Rongguang's argument and Jian Youwen's fascination with the history of the Taiping Heavenly Kingdom all seem to indicate that Christians and people at missionary universities in Guangdong and Hong

\footnotetext{
46 Youwen Jian, "Taiping Tianguo Hongshi Yiyi Fangwen Ji" [Visiting the Descendants of the Taiping Heavenly Kingdom], Taiping Tianguo Zaji: Jintian Zhi You Qita - Taiping Jun Guangxi Shouyi Shi [Random Records on the Taiping Heavenly Kingdom: Outings to Jintian, etc. - History of the Taiping Heavenly Kingdom at Shouyi, Guangxi] 3, no. 64 (1991): 225226. Hong Xiaoyun is not from the same Hong family in Hua Town.

47 Youwen Jian, Taiping Tianguo Quanshi, 1 [Complete History of the Taiping Heavenly Kingdom, Vol.1] (Hong Kong: Jianshi Mengjin Shuwu, 1962), 31-32.

48 Youwen Jian, Zhongguo Jidujiao De Kaishan Shiye [Pioneering Christianity in China] (Hong Kong: Jidujiao Fuqiao Chubanshe, 1960), 23-24.

49 Zhiye Li and Juyan Huang, eds., Jindai Guangdong Jiaoyu Yu Lingnan Daxue [Education in Modern Guangdong and Lingnan University] (Hong Kong: Shangwu Yinshu Guan, 1995), 116.
} 
Kong shared a common view of the Christian connection between the Taiping Heavenly Kingdom and the Xinhai Revolution.

\section{McNeur's The Biography of Liang A-Fa and Its Implications}

The previous section mentioned how Liang A-Fa was made known to society through the efforts of Feng Yangong. Zhang Zhuling's argument regarding the Taiping Heavenly Kingdom and Christianity was also discussed. McNeur's effort to write the biography must be parallel to such environment.

It is difficult to confirm when he started this work. However, one booklet mentioned that McNeur spent over ten years collecting materials about Liang A-Fa. ${ }^{50}$ In addition, Feng Yangong sent a letter to McNeur in 1923 requesting photographic materials. ${ }^{51}$ Also, McNeur stayed in London for treatment of his eyes from 1920 to $1922 .^{52}$ These facts tell us that he started the book after returning to Guangzhou. This section examines the message McNeur attempted to convey through the Biography of Liang A-Fa and the impact this book had on Chinese society.

\section{(1) McNeur's Perception of the Heavenly Kingdom}

MFP has many working notes on McNeur's written works from the 1920s. These notes clarify McNeur's perception of the Heavenly Kingdom. First, he was familiar with the history of the Heavenly Kingdom and recognized the role that Good Words Exhorting the Age played, though his understanding was not a great difference different from that of other missionaries. For example, Yuko Watanabe analyzed the missionary activities of the Chinese Union (established in Hong Kong) in Guangxi, and its influence on the God Worshippers. She also mentioned the missionaries' evaluation of the Heavenly Kingdom. Kenneth S. Latourette (a historian of Christianity in the 20th century) argues that Watanabe's argument is threefold: 1) the Heavenly Kingdom significantly interrupted missionary activities; 2) the influence of Christianity on the Heavenly Kingdom

\footnotetext{
50 "Liang A-fa Lue Shi" [A Brief Biography of Liang A-fa] (Guangdong: Guangdong Chinese Christian Church), 7, Various pamphlets written in Chinese script (MS-1007-003/030), MFP. This pamphlet was probably issued after the Chinese edition of The Biography of Liang A-fa was published in Shanghai.

51 "Feng Yan Gon Zhi Mai Zhan'en Han" [Letter from Feng Yangong to McNeur], September 3, 1923, Papers relating to Leung Faat (MS-1007-003/027), MFP.

52 Henry H. Burton, George Hunter McNeur: A Pioneer Missionary in South China (Christchurch: Presbyterian Bookroom, 1955), 21-22.
} 
had been underestimated; and 3) China increasingly viewed Christianity as an evil religion. ${ }^{53}$

When McNeur mentioned Hong's attitude toward Christianity, he said that "Hong Siu-tuen and his followers would have attained their objective, and opened the country to Christian culture, if they had remained obedient to the vision as it was interpreted by Liang A-fa's little tracts." ${ }^{, 24}$. Here, he seemed to sympathize with Hong and his followers. But following sentence described Hong's inability to understanding Christian doctrine because of the lack of Liang A-Fa's help.

Missionaries have never accepted Hong's view of Christianity, claim as the second son of God, and denial of Trinitarianism.

McNeur, however, was in a different situation from Latourette. Because, he had to explain how mission works in South China influenced Taiping Rebellion within the Liang's biography, specifically. McNeur knew when he starting writing that Hong Xiuqiu had obtained Good Words Exhorting the Age. Pointing out the relationship with the Heavenly Kingdom, he mentioned in his notes that the religious tracts was one of Liang A-Fa's works. ${ }^{55}$ However the English version of the Biography of Liang A-Fa only vaguely talks about this relationship. For example, the original text does not use the name of the book, Good Words Exhorting the Age, but instead only refers to it as a small booklet written by [Liang] A-fa. ${ }^{56}$ Here we cannot identify Good Words Exhorting the Age as a book that symbolizes the continuity from the Heavenly Kingdom to the 1911 Revolution as the Chinese claim.

Second, McNeur also had to pay close attention in the English version of the Biography of Liang A-Fa to separate him from the Heavenly Kingdom and describe him purely as a Christian. Citing Thomas Taylor Meadows, he contrasted Hong Xiuquan and Feng Yunshan's misunderstanding of the Bible with an appraisal of Liang A-Fa's effort to translate Christian principles even if through a series of trial and error. ${ }^{57}$ Regarding Good Words Exhorting the Age he referred to, a missionary in China, Alexander Wylie's work, published at $1867 .{ }^{58}$ McNeur may have wanted to cite from his contemporaries about the Heavenly Kingdom. Yet, as Zhang Zhuling argues, the English edition of the Biography of Liang A-Fa seems to have avoided any clear linkage between Good Words Exhorting the Age and the Heavenly Kingdom. In the initial Chinese edition of the Biography of Liang

53 Yuko Watanabe, "Kirisuto Dendo to Taihei Tengoku" [Christian Missions and the Taiping Heavenly Kingdom], Quadrante 3, (March 2001): 200-201.

${ }^{54}$ McNeur, China's First Preacher, 79.

55 Notebook containing material relating to Leung Ah Faat, MFP.

${ }^{56}$ McNeur, China's First Preacher, 75.

${ }^{57}$ McNeur, China's First Preacher, 78-80.

58 "Rough Draft of 'Reverend Leung Faat, China's First Protestant Evangelist' Volume VI" (MS-1007-003/012), MFP. 
$A-F a$, Zhang argues, "[Liang's] written missionary works ... had helped the great accomplishment of the Heavenly Kingdom's national revolution." ${ }^{, 59}$ In contrast, in the English version published in 1934, McNeur did not touch upon Zhang's evaluation of Liang.

Western understanding of the Heavenly Kingdom also manifests in review articles after the 1934 English edition. One reviewer evaluated McNeur's work as follows: Liang A-Fa's religious booklet was obtained by Hong Xiuquan and eventually caused the violent uprising of the Heavenly Kingdom, which killed 3 million people and debauched Christianity in China. However, Liang did not lend his hand to the Heavenly Kingdom but continued his missionary work, thus fulfilling his duty as a "the greatest preacher." ${ }^{60}$ Reviews show the negative feelings foreigners held for the Heavenly Kingdom at that time. The Biography of Liang $\mathrm{A}-\mathrm{Fa}$ confirms that Liang had nothing to do with the uprising of the God Worshippers, and foreigners lauded Liang because he kept a distance from the Heavenly Kingdom. ${ }^{61}$ It is necessary to point out that the overall context for this praise lies in a firmer belief among Chinese that the Taiping Heavenly Kingdom and the 1911 Revolution were connected through Christianity.

\section{(2 ) After the Publication of the Biography of Liang A-Fa}

The Chinese edition of The Biography of Liang A-Fa was first published in Guangzhou, in 1930 after a long period of writing and historical data collection by McNeur. The second edition was published in Shanghai in $1931 .^{62}$ The English version was also published in Shanghai in 1934. The third edition was in Chinese and was published at Hong Kong in 1955. How did the Chinese people accept the biography of a little known Chinese Christian?

Liang A-Fa became even more famous than the "great men" introduced in this article. The Guangdong Synod of Chinese Christian Church, established a memorial hall in 1931 at Liang A-Fa hometown of Gaoming, Foshan Town. ${ }^{63}$

59 George Hunter McNeur, Liang A-fa Zhuan [The Biography of Liang A-fa], trans. Zhanyun $\mathrm{Hu}$ (Guangzhou: Zhonghua Jidujiao Guangdong Xiehui, 1930), 131.

60 J. D. "An Evangelist," The North China Daily News, June 26, 1934, Miscellaneous papers including photographs, material relating to Leung A-Fa, clippings, and a list of missionaries (MS-1007-005/010), MFP.

61 Other book reviews argue the same. The Chinese Recorder argued that Hong Xiuquan obtained part of the "religious pamphlet" by Liang A-fa, which in a few years led to the armed uprising of the God Worshippers. However, the book does not make any direct reference to Liang A-fa: "Leung A-Fa," The Chinese Recorder, (August 1934): 521-522).

62 McNeur, Zhongguo Zuizao De Budaozhe: Liang Fa [Liang A-fa, The First Chinese Missionary], trans. Zhanyun Hu (Shanghai: Guangxuehui, 1931).

63 "Zhonghua Jidu Jiaohui Guangdong Xiehui Sishinian Lai Zhi Shigong Gaikuang Baogao: 1933-1937" [Construction Report of Kwangtung [Guangdong] Synod of Church of Christ in China, 1933-1937], Shanghai City Archive U102-0-14-119, 5. McNeur and Zhang Zhuling 
With the completion of the memorial hall and publication of the Biography of Liang A-Fa one Chinese Christian said that "it is surprising that Liang A-Fa was not famous before and highly evaluated him as one hundred times more honorable than the martyr Shi Jianru." 64

Yet, in rural areas Liang's work did not strongly relate with the Taiping Heavenly Kingdom. Liang introduced new cultures to China in the late Qing Period and was also the founder of Boji Hospital where Sun Yat-sen had studied. Some praised Liang's significant contribution to the establishment of the Republic of China: "Liang's patriotism and love for his people indirectly contributed to the building of the Republic of China in later years ${ }^{65}$ For people in rural areas, the publication of Liang's biography meant more than a better understanding of Christianity. This is probably due to the efforts of those who had been related to Liang A-Fa since the 1910s.

In the 1960s, alumni at Lingnan University in Hong Kong stated that Zhong Rongguang worked hard to save Liang A-Fa's grave, and there were well over 1,000 people at the anniversary of foundation of Lingnan University in 1920. These alumni did not mention Shi Jianru, who was supposedly the main figure of that event. ${ }^{66}$ Liang overshadowed Shi in descriptions by later generations. Furthermore, in contrast to the amount of effort spent researching Liang's publications, translations, and missionary works, Cai Gao is now only China's first protestant convert.$^{67}$

It is difficult to know to what extent Chinese Christians accepted McNeur's argument that Liang A-Fa was a disciple of Morrison and Milne. Indeed, the Chinese edition of Liang A-fa Chuan published in Hong Kong in 1955, maintains, "Although the movement failed, the Taiping Heavenly Kingdom lasted for 13 years and spread to 19 provinces. Thus, it is safe to conclude that Good Words Exhorting the Age had tremendous influence on the movement." The trend to relate Good Words Exhorting the Age with the revolution existed in Hong Kong Christian circles even after McNeur's death. ${ }^{68}$ The most distinctive point for

were in charge of construction planning and accounting of the Liang A-fa Memorial Hall.

64 Tongyue Cui, "Wei Liang Fa Guli Jiniantang Shuoshuo Bing Tici" [Providing an Epigraph for the Liang A-fa Hometown Memorial Hall], July 1, 1934, in Canghai Shengping [A Hard Life] (Taipei: Longwen Chubanshe, 1994), 84-85. Cui was from the same town of Gaoming as Liang A-fa.

65 "Liang A-fa Lue Shi," 5.

${ }^{66}$ Alumni Association of Hong Kong Lingnan University, 51.

67 Yixiong Wu, Zai Zongjiao Yu Shisu Zhijian: Jidu Xinjiao Chuanjiaoshi Zai Huanan Yanhai De Zaoqi Huodong Yanjiu [Between Religion and the Secular World: Research of the Early Christian Protestant Missionary Activities along the Southern Chinese Coast] (Guangdong: Guangdong Jiaoyu Chubanshe, 2000), 44-45.

68 Yiling Liu, "Chongban Xuyan" [Prologue for the New Edition], in Zhonghua Zuichu De Budaozhe Leung Faat Zhuan: Fu Quanshi Liangyan [Biography of Liang A-fa, the First 
the 1955 edition is that it contained a full volume of Good Words Exhorting the Age. McNeur and other foreigners' evaluations of Liang A-fa as "the greatest missionary" were different from the Christian community in Guangzhou and Hong Kong.

\section{Conclusion}

After the collapse of the Qing Dynasty as a result of the 1911 Revolution, those with Christian backgrounds in Guangdong, Hong Kong, and Macau became known within their local communities. Yet, Liang A-fa became famous through a different means from other "great men" such as Shi Jianru and Cai Gao. In short, Feng Yangong's dissident relating to evaluation of Cai Gao led people at Lingnan University and the Christian community to eventually commemorate Liang A-fa at Lingnan University in 1920. Feng's efforts to award him was not important for Zhang Zhuling, who emphasized the importance of Christianity in the Taiping Heavenly Kingdom. For Zhang in the Guangzhou and Hong Kong Christian community, Liang A-Fa's Good Words Exhorting the Age was the origin of the revolutionary movements that culminated in the 1911 Revolution. Regardless of McNeur's intention, the English edition of the Biography let us understand close relationship between Liang A-fa and the Taiping Heavenly Kingdom.

When viewing the 1911 Revolution from the perspective of a history of Christianity in China. It can be seen that the Taiping Heavenly Kingdom, which initially symbolized the anti-Qing movement, became linked with the Revolution after the discovery of Liang A-Fa, and Christianity was thought to be the origin of the Revolution. The discourse about Taiping Rebellion as a form of propaganda against the Manchus had by then new implications for some Christians once the Qing Dynasty collapsed. It was newly added that the Rebellion was significantly enlightened by Christian ideas. Soon enough, the Christian community in Guangzhou and Hong Kong after the 1910s formed an interpretation that an expansion of Christianity in China would link-the Taiping Heavenly Kingdom and the 1911 Revolution together in the same historical context.

Native Christians' vigourous works among their local society after the demise of the Qing Dynasty and their close ties with the Heavenly Kingdom diverted people's attention to Christianity in the Heavenly Kingdom. In short, against

Missionary in China], trans. Zhanyun Hu (Hong Kong: Jidujiao Fuqiao Chubanshe, 1955), 3. Jidujiao Fuqiao Chubanshe [Christian Fuqiao Press] was established in Hong Kong as part of the Christian Literature Society for Chinese. Li, "Guangxuehui Zhi Fazhan Yu Zhongguo Shiju Zhuanbian Zhi Guanxi,” 288. 
the backdrop of the Chinese Revolution was the process of reconstructing the Heavenly Kingdom prompted by the "discovery" of Liang A-Fa by Chinese Christian.

\section{Bibliography}

Alumni Association of Hong Kong Lingnan University. Zhong Rongguang Xiansheng Zhuan [The Biography of Zhong Rongguang]. Hong Kong: Alumni Association of Hong Kong Lingnan University, 1996.

“A, Shi Jianru Busiyi” [Alas, the Undying Shi Jianru]. Xianggang Huazi Ribao [Hong Kong Chinese Daily], December 26, 1911.

Box, E. "Morrison, Milne, and Medhurst: Three Pioneers of Protestant Missions to China." The Chinese Recorder, (1904):122.

Burton, Henry H. George Hunter McNeur: A Pioneer Missionary in South China. Christchurch: Presbyterian Bookroom, 1955.

"Cai Gao Xiansheng Nianpu" [Cai Gao Biography]. Tongwenbao 630. Miscellaneous papers. McNeur Family Papers. University of Otago, Hocken Collection.

"Cai Gao Xiansheng Shilue" [A Brief Biography of Cai Gao]. Notebook containing material relating to Leung Ah Faat. McNeur Family Papers. University of Otago, Hocken Collection.

Cui, Tongyue. "Wei Leung Ah-Faat Guli Jiniantang Shuoshuo Bing Tici" [Providing an Epigraph for the Leung Ah-Faat Hometown Memorial Hall], July 1, 1934. In Canghai Shengping [A Hard Life]. Taipei: Longwen Chubanshe, 1994.

"Dianlai Jukuan" [Large Amount of Money Wired]. Lingnan Qingnian Bao [Lingnan Youth], October 18, 1917, Page 2.

"Diyi Xuanjiaoshi Leung Ah-Faat Xiansheng Mu" [Leung Ah-Faat: The First Missionary's Grave]. Photographs and papers. McNeur Family Papers. University of Otago, Hocken Collection.

Dunch Ryan, Fuzhou Protestans and the making of a Modern China 1875-1927, New Heaven and Londn:Yale University Press, 2001.

"Feng Yan Gon Zhi Mai Zhan'en Han" [Letter from Feng Yangong to McNeur], September 3, 1923. Papers relating to Leung Faat. McNeur Family Papers. University of Otago, Hocken Collection.

Feng, Ziyou. "A Brief Biography of Shi Jianru." In Geming Yishi 2 [History of the Revolution, Vol. 2]. Beijing: Xinxing Chubanshe, 2009.

"Geihuan Shi Lieshi Chanye" [Returning to Martyr Shi]. Xianggang Huazi Ribao 
[Hong Kong Chinese Daily], March 21, 1913.

$\mathrm{Gu}$, Changsheng. Xuanjiaoshi Yu Jindai Zhongguo [Missionaries and Modern China]. Shanghai: Shanghai Renmin Chubanshe, 1985.

Ike, Ryokichi. Shina Kakumei Jikken Ki [First-Hand Experience of the Xinhai Revolution]. Kaneo Bunen Do, 1911.

J. D. "An Evangelist." North China Daily News, June 26, 1934. Miscellaneous papers including photographs, material relating to Leung A-Fa, clippings, and a list of missionaries. McNeur Family Papers. University of Otago, Hocken Collection.

Jian, Youwen. Taiping Tianguo Quanshi, 1 [Complete History of the Taiping Heavenly Kingdom, Vol. 1]. Hong Kong: Jianshi Mengjin Shuwu, 1962.

Jian, Youwen. "Taiping Tianguo Hongshi Yiyi Fangwen Ji" [Visiting the Descendants of the Taiping Heavenly Kingdom]. Taiping Tianguo Zaji: Jintian Zhi You Qita - Taiping Jun Guangxi Shouyi Shi [Random Records on the Taiping Heavenly Kingdom: Outings to Jintian, etc. - History of the Taiping Heavenly Kingdom at Shouyi, Guangxi] 3, no. 64 (1991): 225-226.

Jian, Youwen. Zhongguo Jidujiao De Kaishan Shiye [Pioneering Christianity in China]. Hong Kong: Jidujiao Fuqiao Chubanshe, 1960.

"Jiangmen Fenxiao Zaizhi" [About the Jiangmen Branch Campus]. Lingnan Qingnian Bao [Lingnan Youth], October 11, 1917, Page 1.

Jidu Jiao Zhongguo Diyi Xuanjiaoshi Leung Ah-Faat Xiansheng Zhuan [Biography of Leung Ah-Faat, the First Missionary in China].

Kaba, Toyohiko. "Kirisuto Kyo to Kindai Chugoku Shakai: Tamashii no Kyuusai kara Shakai no Kyuusai he" [Christianity and Modern Chinese Society: From Salvation of the Soul to the Salvation of Society]. In Ibunka Kouryuu Shi no Saikentou: Nihon Kindai no Keiken to Sono Shuuhen [Reexamining the History of Cross-Cultural Relations: The Experience of Modern Japan and its Periphery], edited by Masaki Hirota and Fuyuhiko Yokota. Heibonsha, 2011.

Kikuchi, Hideaki. "Taihei Tengoku ni Miru Ibunka Juyo" [Taiping Heavenly Kingdom and Acceptance of Different Cultures] Sekaishi Libretto 65 (2003): 14-20.

Koizumi, Tatsuya. "Makao kara no Ahen Mitsuyu Mondai to Igirisu Teikoku: 1913 nen Ahen Kyotei wo Chushin ni" [The Problem of Opium Smuggling from Macau and the British Empire: The Opium Convention of 1913]. In Teikoku no Nagai Kage: 20 Seiki Kokusai Chitsujo no Henyou [The Long Shadow of the Empire: Transformation of the 20th Century International Order], edited by Youichi Kibata and Harumi Gotou, 146. Minerva, 2010.

"Leung A-Fa." The Chinese Recorder, (1934): 521-522.

"Leung Ah-Faat Lue Shi” [A Brief Biography of Leung Ah-Faat]. Guangdong: Guangdong Chinese Christian Church. Various pamphlets written in Chinese 
script. McNeur Family Papers. University of Otago, Hocken Collection.

Leung, Zelan. "Guanyu Leung Ah-Faat Xiansheng Fenmu Shi Laiwang Gongdu Yice" [Official Documents about Leung Ah-Faat's Grave]. In Zhongguo Jiduhui Diyi Xuanjiaoshi Leung Ah-Faat Xiansheng Zhuan Lue [A Brief Biography of the First Chinese Christian Missionary_Leung Ah-Faat], 23-24.

Li, Jinqiang. "Xianggang Daoji Huitang Yu Qingji Geming Xin Yundong" [Hong Kong To Tsai Church and Qingji New Revolutionary Movements]. In Zhongguo Jidujiao Quyushi Yanjiu [Historical Studies of the Chinese Christian Districts], edited by Chen Jianming and Liu Jiafeng, 127-141. Sichuan: Bashu Publisher, 2008.

Li, Zhigang. "Guangxuehui Zhi Fazhan Yu Zhonguo Shiju Zhuanbian Zhi Guanxi" [Relationship between the Development of the Christian Literature Society for Chinese and China's Transformation to a New Era]. In Jidujiao Yu Jidai Zhongguo Wenhua Lunwenji 2 [Collection of Papers on Christianity and Modern Chinese Culture, Vol. 2], edited by Li Zhigang, 284-285. Taiwan: Yuzhouguang Chubanshe, 1989.

Li, Zhigang. "Wanqing Guangdong Jidujiao Jiaoan Zhi Shixi" [A Preliminary Analysis of Anti-Christianity Cases at Guangdong during the Late Qing Era]. In Jidujiao Yu Jidai Zhongguo Wenhua Lunwenji 2 [Collection of Papers on Christianity and Modern Chinese Culture, Vol. 2], edited by Li Zhigang, 143144. Taiwan: Yuzhouguang Chubanshe, 1995.

Li, Zhiye, and Juyan Huang, eds. Jindai Guangdong Jiaoyu Yu Lingnan Daxue [Education in Modern Guangdong and Lingnan University]. Hong Kong: Shangwu Yinshu Guan, 1995.

Lin, Xiyi. "Buwang Zhi Wangshi Shulue" [Brief Recollections]. Jidujiao Zhongguo Diyi Chuanjiaoshi Leung Ah-Faat Zhuan [The Biography of the First Chinese Missionary-Leung Ah-Faat], 27-28. Papers in Chinese script relating to Leung Faat. McNeur Family Papers. University of Otago, Hocken Collection.

Liu, Aosheng. The History of Christian Churches in Hong Kong. Hong Kong: Hong Kong Baptist Church, 1997.

Liu, Chengyu. Taiping Tianguo Zhanshi [War History of the Taiping Heavenly Kingdom]. Zuguo Zazhishe, 1904.

Liu, Yiling. "Chongban Xuyan" [Prologue for the New Edition]. In Zhonghua Zuichu De Budaozhe Leung Ah-Faat Zhuani: Fu Quanshi Leungyan [Biography of Leung Ah-Faat: The First Chinese Missionary], translated by Zhanyun Hu. Hong Kong: Jidujiao Fuqiao Chubanshe, 1955.

Lu, Guanwei. "Xuesheng Yu Guojia" [Students and the Country] Lingnan Qingnian Bao [Lingnan Youth], September 27, 1917, Page 3.

McNeur. Zhongguo Zuizao De Budaozhe: Leung Ah-Faat [Leung Ah-Faat, the 
First Chinese Missionary], translated by Zhanyun Hu. Shanghai: Guangxuehui, 1931.

McNeur, Geo H. [sic]. "Summer Conference for Preachers at Canton." The Chinese Recorder, (1918): 623-624.

McNeur, George Hunter. Leung Ah-Faat Zhuan [The Biography of Leung AhFaat], translated by Zhanyun Hu. Guangzhou: Zhonghua Jidujiao Guangdong Xiehui, 1930.

McNeur, George Hunter. China's First Preacher: Leung A-fa 1789-1855. Shanghai: Kwang Hsueh Publishing House, Oxford University Press, China Agency, 1934.

Namiki, Yorihisa. "“Taihei Tengoku' Zou no Keisei to Henbo" [The Construction and Change of the Image of the "Taiping Heavenly Kingdom"]. In Nen'gun to Kahoku Shakai: Kindai Chugoku ni Okeru Minshu Hanran [Nien Rebellion and the North Chinese Society: Popular Uprising in Modern China]. Kenbun Shuppan, 2010.

Rong, Hong. Seigaku Touzenki [My Life in China and America], translated by Momose Hiromu. Heibonsha, 1969.

"Rongguang Jun Fuhan Zhaolu" [A Record of Rongguang's Letters], August 15, 1917. Zhongguo Jiduhui Diyi Xuanjiaoshi Leung Ah-Faat Xiansheng Zhuan Lue [A Brief Biography of the First Chinese Christian Missionary-Leung AhFaat]. Papers in Chinese script relating to Leung Faat. McNeur Family Papers. University of Otago, Hocken Collection.

"Rough Draft of 'Reverend Leung Faat, China's First Protestant Evangelist' Volume VI." Notebook containing material relating to Leung Ah Faat. McNeur Family Papers. University of Otago, Hocken Collection.

Sun, Jiang. "'Youkyo' to Iu Tasha: 19 Seiki Kouhan ni Okeru Kirisuto Kyo to Chugoku Shakai" ["Foreign Religion" as the Other: Christianity and Chinese Society in the Latter Half of the 19th Century]. Rekishi Gaku Kenkyu [Journal of Historical Studies] 808, (2005): 29.

Tao, Feiya, and Weihua Yang. Jidujiao Yu Zhongguo Shehui Kexue Yanjiu Rumen [Introduction to Christianity and Chinese Society]. Shanghai: Fudan University Chubanshe, 2009.

Tsu, Y. Y. "Progress and Fruits of Christianity in China." In China Mission Year Book, 1913. Shanghai: Christian Literature Society China, 1913.

"Typed Drafts of 'The Church and the Chinese in N.Z."' McNeur Family Papers. University of Otago, Hocken Collection.

Watanabe, Yuko. "Kirisuto Dendo to Taihei Tengoku" [Christian Missions and the Taiping Heavenly Kingdom]. Quadrante 3, (2001): 200-201.

"Weiwo Huaqiao" [Consoling the overseas Chinese], Lingnan Qingnian Bao [Lingnan Youth], March 1, 1918, Page 2. 
Wu, Lingqing. Taiping Tianguo Yeshi [Privately Composed History of the Taiping Heavenly Kingdom]. Shanghai: Zhonghua Shuju, 1923.

Wu, Yixiong. Zai Zongjiao Yu Shisu Zhijian: Jidu Xinjiao Chuanjiaoshi Zai Huanan Yanhai De Zaoqi Huodong Yanjiu [Between Religion and the Secular World: Research of the Early Christian Protestant Missionary Activities along the Southern Chinese Coast]. Guangdong: Guangdong Jiaoyu Chubanshe, 2000.

"Xiaozuri" [School Anniversary]. Lingnan Qingnian Bao [Lingnan Youth], June 24, 1920, Page 2.

Yoshizawa, Seiichiro. Shincho to Kindai Sekai: 19 Seiki [The Qing Dynasty and the Modern World: 19th Century]. Iwanami, 2011.

Zhang, Tingxian (Zhuling). "Beizhi” [Epigraph]. Zhanggong Caiting Jinianbei [The Monument for Zhang Gongcai].

Zhang, Zhuling, and Yaoshi Pi, trans. Zhongguo Jiduhui Diyi Xuanjiaoshi Leung Ah-Faat Xiansheng Zhuan Lue [A Brief Biography of the First Chinese Christian Missionary-Leung Ah-Faat]. Hong Kong: Hong Kong Christian Periodicals of Hong Kong Daguangbao, 1923. Various pamphlets written in Chinese script. McNeur Family Papers. University of Otago, Hocken Collection.

Zhang, Zhuling. "Zhidaotang Zhijin Xitan” [Recollections of Zhidaotang]. Zhidao Annual, December 1928. Annual report of the Chinese Christian Church of Macau. McNeur Family Papers. University of Otago, Hocken Collection.

Zhang, Zhuling. "Lundun Hui Lishi Nan-Zhongguo Fangmian" [History of London Churches in Southern China]. Shanghai City Archive.

Zhang, Zhuling, trans. "Zhonghua Diyi Shouxi Ren Cai Gao Jun Yishi” [Unknown Stories of the First Baptized Chinese: Cai Gao]. In Guangdong Jidu Jiaohui Xiejinhui Baogao 1914 Nian [Guangdong Xiejin Christian Church Report of 1914]. Shanghai City Archive.

"Zhonghua Jidu Jiaohui Guangdong Xiehui Sishinian Lai Zhi Shigong Gaikuang Baogao: 1933-1937' [Construction Report of Kwangtung (Guangdong) Synod of Church of Christ in China, 1933-1937]. Shanghai City Archive.

Zhou, Han. Guijiao Gaisi [The Demons' Call for Death].

Zhu. "Lunshuo: Liyong Jihui Yi Xiqu Aiguo Jingshen" [An Opportunity to be Imbued with Patriotism]. Lingnan Qingnian Bao [Lingnan Youth], October 11, 1917, Page 3. 


\section{About the Author}

Ayumu DOI was born in 1983. He specializes in a history of Christianity in modern and contemporary China. Currently a recipient of the Post-Doctoral Research Fellowship for Young Scientists from the Japan Society for the Promotion of Science, Doi completed his coursework without degree at the Graduate School of Arts and Sciences at the University of Tokyo in March 2013. His articles include, “Shou Kankai no 'Nanen' ni tsuite no Kousatsu: Tounan Ajia Kakyo/Kajin ni Yoru Keiaidou he no Bokin no Kouzu" [Analysis of Zhao Guanhai's 'Nanjuan': Donation from Southeast Asian Ethnic Chinese to the Huiai Church], in Nenpo Chiiki Bunka Kenkyu [Annual Report: Area Cultural Studies] 14 (2010); "Shinmatsu Zaigai Chugokujin to Chugoku Kirisuto Kyo Fukyo Jigyo" [A Study on the Missionary Movement in China Involved with Overseas Chinese: the Canton Villages Mission and Chinese in New Zealand], The Toyo Gakuho (Journal of the Research Department at the Toyo Bunko) 94, no. 3 (2012); "Chugoku Kirisuto Shi kara Mita Shingai Kakumei” [Xinhai Revolution from the Historical Perspective of Chinese Christianity], in Guroubaru to Hsutori no Nakano Shingai Kakumei [Xinhai Revolution in the Global and Historical Context], (Nihon Sonbun Kenkyu Kai, 2013).

Email:ayumudoi0208@hotmail.com 